\title{
Analysis and modeling of ducted and evanescent gravity waves observed in the Hawaiian airglow
}

\author{
D. B. Simkhada ${ }^{1}$, J. B. Snively ${ }^{1}$, M. J. Taylor ${ }^{1}$, and S. J. Franke ${ }^{2}$ \\ ${ }^{1}$ Utah State University, Center for Atmospheric and Space Sciences, 4405 Old Main Hill, Logan, UT 84322-4405, USA \\ ${ }^{2}$ University of Illinois at Urbana-Champaign, Department of Electrical and Computer Engineering, 320 CSL, 1308 W. Main \\ Street, Urbana, IL 61801, USA
}

Received: 4 November 2008 - Revised: 24 April 2009 - Accepted: 29 April 2009 - Published: 19 August 2009

\begin{abstract}
Short-period gravity waves of especially-small horizontal scale have been observed in the Maui, Hawaii airglow. Typical small-scale gravity wave events have been investigated, and intrinsic wave propagation characteristics have been calculated from simultaneous meteor radar wind measurements. Here we report specific cases where wave structure is significantly determined by the local wind structure, and where wave characteristics are consistent with ducted or evanescent waves throughout the mesopause region. Two of the documented events, exhibiting similar airglow signatures but dramatically different propagation conditions, are selected for simple numerical modeling case studies. First, a Doppler-ducted wave trapped within relatively weak wind flow is examined. Model results confirm that the wave is propagating in the $85-95 \mathrm{~km}$ region, trapped weakly by evanescence above and below. Second, an evanescent wave in strong wind flow is examined. Model results suggest an opposite case from the first case study, where the wave is instead trapped above or below the mesopause region, with strong evanescence arising in the $85-95 \mathrm{~km}$ airglow region. Distinct differences between the characteristics of these visibly-similar wave events demonstrate the need for simultaneous observations of mesopause winds to properly assess local propagation conditions.
\end{abstract}

Keywords. Atmospheric composition and structure (Airglow and aurora) - Meteorology and atmospheric dynamics (Middle atmosphere dynamics; Waves and tides)

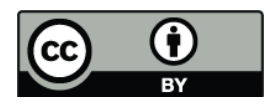

Correspondence to: D. B. Simkhada (d.simkhada@aggiemail.usu.edu)

\section{Introduction}

Gravity waves in the atmosphere provide significant and important dynamic coupling between horizontally and vertically separated atmospheric regions. Even under ideal windless and inviscid conditions, upward propagation through exponentially decreasing atmospheric density will result in exponential increase in wave velocity perturbations, conserving kinetic energy with altitude (e.g., Gossard and Hooke, 1975), and leading ultimately to breaking and deposition of momentum and energy (e.g., Fritts and Alexander, 2003, and references cited therein). Understanding the local propagation characteristics of gravity waves is very important, because under certain conditions, gravity waves are able to transport energy and momentum vertically, and under other conditions they can be trapped (ducted), confining the major flow of wave energy and momentum to a limited range of altitude, and allowing long-range horizontal propagation (e.g., Walterscheid et al., 2000).

Upward propagating gravity waves in the atmosphere are highly influenced by thermal structure and background winds. Atmospheric gravity waves may be subject to ducting in a stably stratified atmosphere that contains levels of temperature or wind maxima or minima. Gravity waves propagate in the vertical direction when the vertical wavenumber is real and the magnitude of intrinsic frequency is less than the Brunt-Väisälä frequency, $N$, and they become evanescent when the vertical wavenumber is imaginary and the intrinsic frequency exceeds the Brunt-Väisälä frequency, $N$ (Chimonas and Hines, 1986). Ducting of gravity waves can occur in a region of propagation sandwiched between two regions of evanescence. The background winds Doppler-shift intrinsic frequency as they vary in the direction of wave propagation. Ducting that is facilitated by wind flow is commonly referred to as Doppler ducting (Chimonas and Hines, 1986; Isler et al., 1997; Snively et al., 2007). Ducting due to

Published by Copernicus Publications on behalf of the European Geosciences Union. 
temperature gradients (leading to variation in Brunt-Väisälä frequency) over altitude is called thermal ducting (e.g., Walterscheid et al., 2001; Snively and Pasko, 2008, and references cited therein). In the case of thermal ducting, the region of propagation occurs in the vicinity of a local maximum in the Brunt-Väisälä frequency, surrounded by regions of relatively low static stability, or even instability.

There has been considerable theoretical research on wave ducting mechanisms in the upper atmosphere (e.g., Chimonas and Hines, 1986; Fritts and Yuan, 1989; Walterscheid et al., 2001; Snively and Pasko, 2008, and references cited therein). Some of these studies considered the existence of ducts caused by thermal gradients or variations in the background winds causing Doppler ducts. Observations in the airglow layers, and numerical model simulations, confirm that atmospheric gravity waves may be thermally ducted (Walterscheid et al., 1999; Hecht et al., 2001; Walterscheid et al., 2001; Yu and Hickey, 2007; Snively and Pasko, 2003, 2008) and/or Doppler-ducted (Isler et al., 1997; Hickey, 2001; Snively et al., 2007). Airglow imaging provides an important tool for determining horizontal characteristics and the occurrence of small-scale, short-period waves at the emission altitudes (Taylor and Edwards, 1991; Taylor et al., 1995, 1997). It has been noted that the observed phase speed and wave period may differ significantly from the intrinsic phase speed and wave period due to the presence of background winds. When airglow image data are combined with simultaneous wind measurements, intrinsic wave parameters can be investigated over a range of heights $(80-100 \mathrm{~km})$, permitting a study of the propagation and ducting characteristics of the wave motions and a more precise comparison with theoretical predictions. A study by Isler et al. (1997), using simultaneous imager observations of gravity waves and MF radar wind data obtained at Maui from 80 and $100 \mathrm{~km}$ altitude suggested that Doppler wave ducts commonly form due to the variation of the background mesospheric wind, such as that arising from the local tidal fields (Snively et al., 2007).

As part of Maui-MALT program, we have utilized novel airglow image data from Maui, Hawaii to investigate shortperiod, small-scale, gravity wave parameters using sequential measurements in the $\mathrm{OH}$ and $\mathrm{O}_{2}$ emission layers in the mesopause region. Coincident meteor radar wind measurements have been used to investigate the intrinsic properties of the wave events and to assess their ducting or evanescence characteristics. Here we present in particular the observed ducted and evanescent wave events. We focus on one example Case Study of Doppler ducting, and another example Case Study of evanescence, induced by the local wind structure. The ducting was associated with maxima and minima of the background wind speed as measured in the direction of wave propagation, and evanescence was associated with the maxima of background wind in the opposite direction of wave motion. We describe the Instrumentation and Methodology of airglow imaging of wave events simultaneously in $\mathrm{OH}$ and $\mathrm{O}_{2}$ emissions and meteor radar wind measurements in Sect. 2. This is followed by the Data and Analysis in Sect. 3, including summaries of ducted and evanescent wave observations in tabular form. Results and Discussion pertaining to the analyses of two observed wave events, and numerical model case studies, are presented in Sect. 4. These are followed by Conclusions in Sect. 5 .

\section{Instrumentation and methodology}

\subsection{Mesospheric temperature mapper}

The Utah State University (USU) Mesospheric Temperature Mapper (MTM) is a high performance CCD imager that was operated as part of the Maui-MALT program at the US Air Force AEOS Facility located at the summit of Haleakala Crater, Maui, Hawaii $\left(20.7^{\circ} \mathrm{N}, 156.3^{\circ} \mathrm{W}\right)$ from November 2001 to December 2006. The MTM utilizes a large format $\left(6.45 \mathrm{~cm}^{2}\right), 1024 \times 1024$ pixel CCD array coupled to a wideangle $\left(90^{\circ}\right.$ circular field of view) telecentric lens system to observe selected emission lines in the $\mathrm{OH}(6,2)$ Meinel band the $\mathrm{O}_{2}(0,1)$ Atmospheric band. The high quantum efficiency ( $\sim 50 \%$ at near infrared wavelengths) and low noise characteristics (dark current $\sim 0.1$ electron per pixel per second at $-500 \mathrm{C}$ ) of the $\mathrm{CCD}$ array provide an exceptional capability for precise nocturnal measurements of $\mathrm{OH}$ and $\mathrm{O}_{2}$ emission intensities $(<0.5 \%$ in $1 \mathrm{~min})$ and derived rotational temperatures $(<1-2 \mathrm{~K}$ in $3 \mathrm{~min})$.

Sequential exposures were made using a temperature stabilized filter wheel fitted with narrow band $(\lambda \sim 1.2 \mathrm{~nm})$ filters centered on the $\mathrm{P}_{1}(2)$ and $\mathrm{P}_{1}(4)$ doublet lines of $\mathrm{OH}(6,2)$ Meinel band at 840 and $846.5 \mathrm{~nm}$ and two well-defined regions of the $\mathrm{O}_{2}(0,1)$ atmospheric band at 866 and $868 \mathrm{~nm}$. To monitor sky conditions and measure any background contribution, a separate background measurements was made at $857.0 \mathrm{~nm}$. Each emission was observed for $60 \mathrm{~s}$ followed by a background sky measurement, resulting in a total cycle time of $\sim 5.5 \mathrm{~min}$. To enhance the precision of the temperature determinations the signal to noise ratio (SNR) of the data were increased by $8 \times 8$ binning on the chip to form a $128 \times 128$ super-pixel image with a resultant zenithal foot print of about $0.9 \times 0.9 \mathrm{~km}$. Rotational temperatures are then computed separately for both emissions using the ratio method, as described eloquently by Meriwether (1984). This solid state imaging system is capable of determining wave-induced fluctuations in the emission intensity and rotational temperature of the near infrared $\mathrm{OH}(6,2)$ Meinel band and the $\mathrm{O}_{2}(0,1)$ Atmospheric band centered at mean heights of 87 and $94 \mathrm{~km}$, respectively. The details of the MTM data reduction and analysis method are given in Pendleton et al. (2000) and Taylor et al. $(1999,2001)$. Data were stored locally on computer disk and downloaded at regular intervals via the internet to USU for subsequent analysis.

Here, the dataset obtained from the Mesospheric Temperature Mapper (MTM) was utilized to investigate horizontal 
parameters of small-scale, short-period waves in both $\mathrm{OH}$ and $\mathrm{O}_{2}$ airglow emissions, and to determine height-averaged temperatures at two altitudes to estimate local stability conditions under which the waves propagated.

\subsection{Meteor radar}

As a part of Maui-MALT program, the University of Illinois (UIUC) meteor radar is located at Maui, Hawaii to provide the measurements of mesopause region winds. The system is a SKiYMET radar (Hocking et al., 2001) operating at $40.92 \mathrm{MHz}$. A single three-element Yagi antenna directed toward the zenith is used to illuminate meteor trails. Meteor trail reflections are coherently detected on five three-element Yagi antennas oriented along two orthogonal baselines, with one antenna in the center of the array common to both baselines. On each baseline the outer antennas are separated from the center antenna by 1.5 and 2.0 wavelengths, respectively. This configuration minimizes antenna coupling, provides enough redundancy to unambiguously determine the azimuth and elevation of most echoes, and provides excellent angular resolution for position determination. The average transmitted power is approximately $170 \mathrm{~W}$, resulting from a $13.3 \mu$ s pulse length, $6 \mathrm{~kW}$ peak envelope power, and an inter-pulse period (IPP) of $466 \mu \mathrm{s}$. Returns are sampled every $13.3 \mu \mathrm{s}$, resulting in $2 \mathrm{~km}$ range resolution. The relatively short IPP causes meteor echoes to be aliased in range; however, the narrow height distribution of meteor echoes combined with precise azimuth and elevation angle measurement allows any range ambiguities to be resolved. The algorithms used to determine the meteor trail position and Doppler shift are described in detail in Hocking and Thayaparan (1997).

Wind velocities are estimated from the trail positions and Doppler shifts using a weighted least squares fit to an assumed constant wind vector composed of eastward and northward components, where the vertical wind is assumed to be negligible. The wind vector fit is based on echoes collected within $1 \mathrm{~h}$ time bins. Height resolution of the estimated winds is determined by a triangular height weighting function with $3 \mathrm{~km}$ half-width and base-width $6 \mathrm{~km}$. The center of the height weighting function is stepped in $1.0 \mathrm{~km}$ increments to provide wind estimates at $1 \mathrm{~km}$ height intervals throughout the $80-100 \mathrm{~km}$ range. The height resolution that can be achieved by the meteor radar is limited by uncertainty in the measured distance to the meteor trail and in the estimated zenith angle of the detected meteor trails. The detailed procedures are described by Franke et al. (2005). Since May 2002 , the optical measurements were complemented by continuous meteor radar observations of the $\sim 80-100 \mathrm{~km}$ wind field over Maui, HI. The standard format provides hourly winds data in the altitude range $80-100 \mathrm{~km}$, sampled every $1 \mathrm{~km}$.

This paper focuses on investigation of the propagation characteristics of very small-scale waves (wavelength, propagation direction, phase speed, and period) derived from
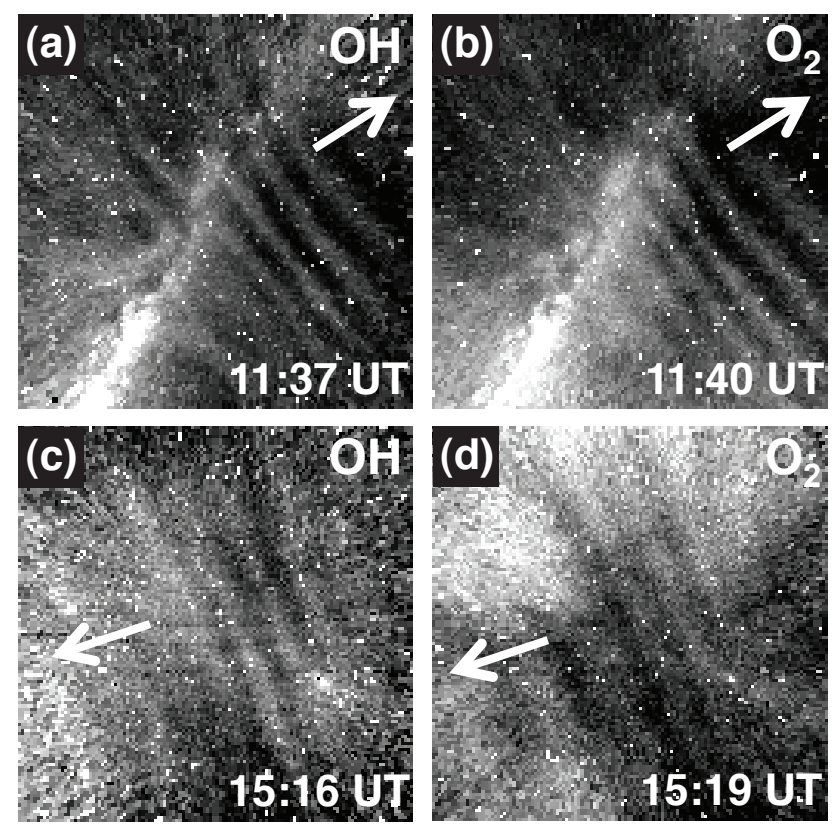

Fig. 1. Flat-fielded and unwarped airglow images obtained at Maui, HI, for the two case study events explored in this paper. Panels (a) and (b) depict $\mathrm{OH}$ and $\mathrm{O}_{2}$ emissions, respectively, of Dopplerducted wave observed on 5 July 2003. Panels (c) and (d) depict $\mathrm{OH}$ and $\mathrm{O}_{2}$ emissions, respectively, of evanescent wave observed on 30 November 2003.

MTM data obtained during 2003. These novel low-latitude data were then compared with coincident meteor radar measurements of horizontal hourly winds from $80-100 \mathrm{~km}$ to obtain intrinsic wave parameters.

\section{Data and analysis}

Airglow imaging measurements provide unique datasets for investigating characteristics of observed small-scale ducted and evanescent waves simultaneously in $\mathrm{OH}$ and $\mathrm{O}_{2}$ airglow layers in the mesopause region. Each image of a circular $90^{\circ}$ field of view was flat-fielded in order to correct the nonuniform intensity in the image. Next, the flat-fielded images were calibrated using the background star-field in order to get a geographic orientation (north on top and south on bottom). The calibrated flat-fielded images were then unwarped by projecting onto a rectangular grid of size $180 \mathrm{~km} \times 180 \mathrm{~km}$ (Garcia et al., 1997; Pautet and Moreels, 2002). To measure the propagation direction and the horizontal wavelength of waves, a 3-D Fast Fourier Transform (FFT) spectral analysis was used to process unambiguous spectrum for a series of pictures (Garcia et al., 1997; Coble et al., 2003). To determine the phase speeds of the observed waves, the displacement of a selected wave front from one image to the next was 
measured through a series of images using a line drawing method. The observed periods were then calculated from measured wavelengths and phase speeds. We have estimated lifetimes of the wave events by observing the sequence of $\mathrm{OH}$ and $\mathrm{O}_{2}$ images in $\sim 5.5 \mathrm{~min}$ interval of time. The University of Illinois meteor radar provided continuous hourly wind measurements over the altitude range of $80-100 \mathrm{~km}$, and was used to investigate the Doppler ducting and evanescence of the observed waves.

Vertical structure of waves can be estimated under the Boussinesq approximation, using the Taylor-Goldstein equation from the linear, irrotational and inviscid equations of motion in an incompressible and stratified atmosphere (Nappo, 2002). The Taylor-Goldstein equation for the vertical perturbation velocity $w_{z}$ is

$$
\begin{aligned}
\frac{d^{2} w_{z}}{d z^{2}}+ & {\left[\frac{N^{2}}{\left(c-u_{o}\right)^{2}}+\frac{1}{\left(c-u_{o}\right)} \frac{d^{2} u_{o}}{d z^{2}}\right.} \\
& \left.-\frac{1}{H\left(c-u_{o}\right)} \frac{d u_{o}}{d z}-k^{2}-\frac{1}{4 H^{2}}\right] w_{z}=0
\end{aligned}
$$

where $N$ is the Brunt-Väisälä frequency, $c$ is observed phase speed, $u_{o}$ is the background wind in the direction of wave propagation; $\hat{\omega}=\omega-u_{o} k$ is the intrinsic frequency of wave, $k=2 \pi / \lambda_{x}$ is the horizontal wavenumber and $H$ is the scale height. After neglecting the curvature and vertical shear terms, the local vertical wavenumber squared $\mathrm{m}^{2}$ for the Taylor-Goldstein Eq. (1) is given by

$m^{2}=\frac{N^{2}}{\left(c-u_{o}\right)^{2}}-k^{2}-\frac{1}{4 H^{2}}$

Here both $N^{2}$ and $u_{o}$ vary smoothly and gradually with altitude. By computing the local profiles of $\mathrm{m}^{2}$, the boundary conditions of ducting regions can be inferred (Isler et al., 1997; Snively et al., 2007). A wave is vertically propagating where $m^{2}>0$ and evanescent where $m^{2}<0$, and the wave can be ducted in a region of vertical propagation $\left(m^{2}>0\right)$ bounded by regions of evanescence $\left(m^{2}<0\right)$. Alternating regions of evanescence and propagation may arise due to variation in the wind $\left(u_{o}(z)\right)$ or Brunt-Väisälä frequency $(N(z))$. In our analysis here, we have computed $m^{2}$ from Eq. (2) using airglow image data to measure ground-relative wave characteristics, and meteor radar data to provide background wind in the direction of wave propagation.

Brunt-Väisälä frequency $(N(z))$ as function of altitude is obtained from the MSISE-90 atmospheric model (Hedin, 1991) and scale height $(H)$ is taken to be $6 \mathrm{~km}$ in the mesopause region. It is here assumed that the variations in wind field $\left(u_{o}\right)$ will dominate over variations in $N$, leading to the formation of Doppler ducts (Isler et al., 1997). This is not always the case in the presence of strong temperature inversion layers (e.g., Chu et al., 2005), which lead to regions of high stability that can form thermal ducts. For the cases modeled here, MTM data is used to confirm relatively weak temperature gradients, suggesting that significant inversions were not likely present at times of these events, and that MSISE-90 data will provide a good approximation of local thermal conditions. The approximate local Brunt-Väisälä frequency squared can be determined from temperature as

$N^{2}=\frac{g}{T}\left(\frac{d T}{d z}+\frac{g}{c_{p}}\right)$,

where $g$ is the acceleration of gravity, $c_{p}$ is the specific heat, $T$ is temperature and $d T / d z$ is the slope between temperature data points measured from $\mathrm{OH}$ and $\mathrm{O}_{2}$ airglow layers by the MTM (Nappo, 2002, p.19). This simple analysis is insufficient to eliminate the possibility of thermal ducting, but it does provide insight into the conditions present within the airglow region, confirming that steep gradients are unlikely to exist. Although temperatures measured do not agree entirely with MSISE-90 data, the similar $N^{2}$ values and temperature gradients suggest that it serves as a reasonable approximation.

The background wind in the direction of wave propagation $\left(u_{o}(z)\right)$, as measured clockwise from north, is calculated from meteor radar data as

$u_{o}(z)=u_{x}(z) \sin \theta+u_{y}(z) \cos \theta$,

where $u_{x}$ and $u_{y}$ are zonal and meridional components of observed wind profile, respectively. The calculated wind $u_{o}(z)$ is then used to determine wave characteristics, as shown in Figs. 2 and 3, and summarized in Table 1. The numerical model requires use of a smoothed wind field (hence $U_{o}(z)$ ), which is derived from fitting an analytical function to the observed wind profiles $u_{o}(z)$. For the analytical modeled wind structure, we fit a function to approximate a tidal wind field, given as

$U_{o}(z)=U_{b g}+\hat{U} \exp \frac{\left(z-z_{o}\right)}{2 H} \cos \left[K_{z}\left(z-z_{o}\right)\right]$,

where $U_{b g}$ is the unperturbed mean background wind, $\hat{U}$ is large-scale background wave's horizontal wind perturbation amplitude at the reference height $\left(z_{o}\right)$, and vertical wavenumber $K_{z}$ is taken to correspond to a vertical wavelength $\Lambda_{z}=2 \pi / K_{z}$. The parameters are obtained by fitting, such that the peak of the wind agrees with measured wind at reference height $z_{o}$, such that $U_{o}\left(z_{o}\right)=U_{b g}+\hat{U}$, where wavelength is obtained by direct measurement of the wind profile. The analytical wind model is then used to derive the TaylorGoldstein vertical wavenumber squared $\left(\mathrm{m}^{2}\right)$ for small-scale waves from Eq. (2), to compare with that derived from the measured wind field, and to confirm agreement. The measurements errors for zonal and meridional winds are calculated as the standard deviation and then measurement uncertainties are estimated as the standard deviation of the mean in the data analysis. The functions obtained are used as a basis for the numerical model background wind field, where they are enveloped within a secant-squared function to limit 
growth of the analytical wind profile above mesopause. This envelope function is given by $\operatorname{sech}^{2}\left(\left(z-z_{o}\right) / 20 \mathrm{~km}\right)$, leading to approximately zero wind at upper and lower model domain boundaries.

We have examined the ducting and evanescence characteristics of small-scale waves, as determined by the meteor radar measurements of hourly background wind along the direction of wave propagation for each event. A total of 15 small-scale wave events, 9 events were Doppler ducted and 6 events were evanescent. The waves investigated simultaneously in $\mathrm{OH}$ and $\mathrm{O}_{2}$ emissions during 2003-2004 exhibited horizontal wavelengths $\lambda_{x} \approx 15-20 \pm 1 \mathrm{~km}$, observed phase speeds $c \approx 25-50 \pm 3 \mathrm{~m} / \mathrm{s}$, observed periods $\tau \approx 7-12 \pm 1 \mathrm{~min}$. We have presented one Doppler ducted event and one evanescent event, each observed simultaneously in $\mathrm{OH}$ and $\mathrm{O}_{2}$ airglow emissions shown in Fig. 1. The average measurement errors calculated as standard deviation for the horizontal wavelength, phase speed, propagation direction and observed period were $1 \mathrm{~km}, 3 \mathrm{~m} / \mathrm{s}, 4^{\circ}$ and $1 \mathrm{~min}$, respectively. Here we have presented the results of the background winds in the direction of wave propagation as measured by the meteor radar, intrinsic phase speeds, intrinsic periods and Doppler-shifted intrinsic frequencies of two wave events. Table 1 lists the observed horizontal wavelength, wave propagation direction, observed horizontal phase speed and observed period of the wave events recorded in both $\mathrm{OH}$ and $\mathrm{O}_{2}$ emissions.

It is important to note that none of the wave events examined here have characteristics of mesospheric bore events (e.g., Taylor et al., 1995; Dewan and Picard, 1998), which are also likely consistent with strongly-ducted waves, although exhibiting distinctive dispersion characteristics and front-like structure. Many waves reported here appear with relatively gradual onset and varying magnitudes over the duration of the event. They occur under various wind conditions, although often following transitions of background wind fields that may contribute to the upward propagation of the waves from lower altitudes. We examine in particular two cases. First, where the wave is ducted near mesopause, although able to tunnel upward into the duct, due to relatively weak evanescence at the lower boundary. Second, where the wave is evanescent throughout the mespause region, although able to tunnel into this region from above or below (e.g., Sutherland and Yewchuk, 2004).

The average observed horizontal wavelengths of the events reported here were similar to those of ripples, but the durations of these events were much longer $(>2 \mathrm{~h})$ than typical short-lived ripple features $(<45 \mathrm{~min})$, with larger spatial extents, and well-defined horizontal phase velocities. For the event of 5 July, the wind field was able to cause ducting of the small-scale gravity wave in the plane of wave propagation (Chimonas and Hines, 1986; Isler et al., 1997; Snively et al., 2007). Given the strong negative background wind flow for the event of 30 November, the small-scale, short-period gravity wave was evanescent in nature. Detailed data analyses and numerical modeling results for these ducted and evanes- cent wave events are discussed below in Sect. 4, including two numerical case studies in which comparable waves are simulated.

\section{Results and discussion}

\subsection{July 2003: ducted wave event}

Figure $1 \mathrm{a}$ and $1 \mathrm{~b}$ shows extensive and distinct small-scale gravity wave structure imaged respectively in the $\mathrm{OH}$ emission at 11:37 UT and the $\mathrm{O}_{2}$ emission at 11:40 UT. This prominent wave event was seen extending over the entire field of view with similar horizontal scale to "ripple" waves (Hecht, 2004). The wave was observed for $174 \mathrm{~min}$ from 10:51 to 13:45 UT in $\mathrm{OH}$ emission and from 10:54 to $13: 48 \mathrm{UT}$ in $\mathrm{O}_{2}$ emission. In both $\mathrm{OH}$ and $\mathrm{O}_{2}$ emissions, the wave was seen progressing northeast at $\sim 50^{\circ} \pm 4^{\circ}$ as measured clockwise from north. The arrow indicates the direction of propagation of the wave. The average phase speeds of 37 and $36 \mathrm{~m} / \mathrm{s}$ with equal horizontal wavelength of $\sim 15 \pm 1 \mathrm{~km}$ were measured in $\mathrm{OH}$ and $\mathrm{O}_{2}$ emissions, suggesting an observed period of $\sim 7 \pm 1 \mathrm{~min}$.

Figure $2 \mathrm{a}$ shows the vertical profile of background wind $\left(u_{o}(z)\right)$ and modeled wind $\left(U_{o}(z)\right)$ projected along the observed direction of wave propagation, and derived from hourly meteor radar wind data at the time 12:00-13:00 UT of the wave occurrence. The wind profile exhibited maximum positive flow of $\sim 12 \mathrm{~m} / \mathrm{s}$ at $92 \mathrm{~km}$ height, and gradually decreased above and below to minimum speeds of $\sim-33 \mathrm{~m} / \mathrm{s}$ at $82 \mathrm{~km}$ and $\sim-36 \mathrm{~m} / \mathrm{s}$ at $99 \mathrm{~km}$. For this analysis, we estimated the measurement uncertainty as the standard deviation of the mean to be $\sim 4 \mathrm{~m} / \mathrm{s}$ for zonal and meridional winds between 80 and $100 \mathrm{~km}$.

In order to derive the local vertical wavenumber squared $\left(\mathrm{m}^{2}\right)$ these values of background winds $\left(u_{o}\right)$ together with observed horizontal wavenumbers $\left(k=2 \pi / \lambda_{x}\right)$, a scale height $(H)$ of $6 \mathrm{~km}$ and static stability, $N^{2}$ in the mesopause region were inserted into Eq. (2). The profile of $N^{2}$ was derived from MSISE-90 atmospheric model temperature profile over $80-100 \mathrm{~km}$ altitude at 12:00 UT as shown in Fig. 4a. To confirm that the MSISE-90 data was approximately valid for these observations, the average Brunt-Väisälä frequency was also derived from MTM temperature data. The $\mathrm{OH}$ and $\mathrm{O}_{2}$ temperatures were found to be $210 \mathrm{~K}$ and $206 \mathrm{~K}$, respectively, leading to an average $N^{2}$ of $0.000404 \mathrm{~s}^{-2}$, consistent with the MSIS model data. The small temperature gradient suggests that significant inversion layers were not present in the airglow region during the time of the event.

Shown in Fig. 2b, the computed values of vertical wavenumber squared are positive $\left(m^{2}>0\right)$ at $85-95 \mathrm{~km}$ height range where the positive peak of $m^{2} \sim 6.8 \times 10^{-7} \mathrm{~m}^{-2}$ occurred at $\sim 92 \mathrm{~km}$. The vertical wavenumber squared of the ducted wave approaches negative at altitudes of reflecting levels $\sim 84$ and $\sim 96 \mathrm{~km}$ where the background wind 
Table 1. Data summary of horizontal wave parameters, as determined from the image data, including date of occurrence, duration, horizontal wavelength $\left(\lambda_{x}\right)$, direction of propagation $(\theta)$, phase speed $(c)$, observed period $(\tau)$ and ducted or evanescent status for the $80-100 \mathrm{~km}$ altitude range.

\begin{tabular}{|c|c|c|c|c|c|c|c|}
\hline Date & Time (UT) & Emission & $\lambda_{x} \pm 1(\mathrm{~km})$ & $\theta \pm 4$ (deg.) & $c \pm 3(\mathrm{~m} / \mathrm{s})$ & $\tau \pm 1(\min )$ & Ducted/Evanescent \\
\hline \multirow[t]{2}{*}{28 Apr 2003} & $10: 00-13: 23$ & $\mathrm{OH}$ & 20 & 46 & 50 & 6.7 & Ducted \\
\hline & $09: 57-13: 26$ & $\mathrm{O}_{2}$ & 20 & 45 & 50 & 6.7 & \\
\hline \multirow[t]{2}{*}{4 May 2003} & $10: 41-13: 12$ & $\mathrm{OH}$ & 19 & 88 & 47 & 6.7 & Ducted \\
\hline & $10: 44-13: 15$ & $\mathrm{O}_{2}$ & 19 & 87 & 46 & 6.9 & \\
\hline \multirow[t]{2}{*}{23 May 2003} & 07:22-11:09 & $\mathrm{OH}$ & 16 & 52 & 32 & 8.3 & Evanescent \\
\hline & $07: 25-11: 12$ & $\mathrm{O}_{2}$ & 16 & 54 & 33 & 8.1 & \\
\hline \multirow[t]{2}{*}{25 Jun 2003} & 06:17-08:08 & $\mathrm{OH}$ & 18 & 210 & 42 & 7.1 & Evanescent \\
\hline & 06:20-08:11 & $\mathrm{O}_{2}$ & 18 & 208 & 41 & 7.3 & \\
\hline \multirow[t]{2}{*}{30 Jun 2003} & $12: 12-14: 37$ & $\mathrm{OH}$ & 19 & 65 & 46 & 6.9 & Ducted \\
\hline & $12: 15-14: 40$ & $\mathrm{O}_{2}$ & 19 & 66 & 46 & 6.9 & \\
\hline \multirow[t]{2}{*}{$5 \mathrm{Jul} 2003$} & $10: 51-13: 45$ & $\mathrm{OH}$ & 15 & 50 & 37 & 6.8 & Ducted \\
\hline & $10: 54-13: 48$ & $\mathrm{O}_{2}$ & 15 & 51 & 36 & 7.0 & \\
\hline \multirow[t]{2}{*}{25 Aug 2003} & $10: 53-15: 08$ & $\mathrm{OH}$ & 16 & 85 & 38 & 7.0 & Ducted \\
\hline & $10: 56-15: 11$ & $\mathrm{O}_{2}$ & 16 & 84 & 37 & 7.2 & \\
\hline \multirow[t]{2}{*}{5 Sep 2003} & $10: 53-15: 09$ & $\mathrm{OH}$ & 20 & 50 & 27 & 12.3 & Ducted \\
\hline & $10: 56-15: 12$ & $\mathrm{O}_{2}$ & 20 & 51 & 28 & 11.9 & \\
\hline \multirow[t]{2}{*}{25 Nov 2003} & $13: 26-15: 40$ & $\mathrm{OH}$ & 17 & 208 & 32 & 8.9 & Evanescent \\
\hline & $13: 29-15: 43$ & $\mathrm{O}_{2}$ & 17 & 210 & 30 & 9.4 & \\
\hline \multirow[t]{2}{*}{30 Nov 2003} & $13: 20-15: 40$ & $\mathrm{OH}$ & 17 & 250 & 25 & 11.3 & Evanescent \\
\hline & $13: 23-15: 43$ & $\mathrm{O}_{2}$ & 17 & 251 & 25 & 11.3 & \\
\hline \multirow[t]{2}{*}{13 Dec 2003} & $04: 45-07: 11$ & $\mathrm{OH}$ & 20 & 255 & 36 & 9.4 & Ducted \\
\hline & $04: 28-07: 14$ & $\mathrm{O}_{2}$ & 20 & 254 & 37 & 9.7 & \\
\hline \multirow[t]{2}{*}{11 Mar 2004} & $05: 37-07: 45$ & $\mathrm{OH}$ & 18 & 265 & 32 & 9.4 & Ducted \\
\hline & $05: 40-07: 48$ & $\mathrm{O}_{2}$ & 18 & 263 & 31 & 9.7 & \\
\hline \multirow[t]{2}{*}{24 Apr 2004} & $08: 47-14: 02$ & $\mathrm{OH}$ & 18 & 40 & 30 & 10.0 & Ducted \\
\hline & $08: 51-14: 05$ & $\mathrm{O}_{2}$ & 18 & 38 & 31 & 9.7 & \\
\hline \multirow[t]{2}{*}{15 Jun 2004} & $12: 05-14: 30$ & $\mathrm{OH}$ & 17 & 38 & 41 & 6.9 & Evanescent \\
\hline & $12: 08-14: 33$ & $\mathrm{O}_{2}$ & 17 & 37 & 40 & 7.1 & \\
\hline \multirow[t]{2}{*}{22 Nov 2004} & $11: 02-15: 41$ & $\mathrm{OH}$ & 19 & 235 & 42 & 7.5 & Evanescent \\
\hline & $11: 05-15: 44$ & $\mathrm{O}_{2}$ & 19 & 232 & 41 & 7.7 & \\
\hline
\end{tabular}

speed becomes abruptly negative in the direction of wave motion. The negative background winds at height ranges of 80-84 and 96-100 km lead to negative $\mathrm{m}^{2}$, forming an evanescent boudary region on both sides of the ducting region. The minimum value of intrinsic phase speed $\left(c-u_{o}\right)$ was $\sim 25 \mathrm{~m} / \mathrm{s}$, occurring at maximum $m^{2}$ at the center of the duct $(92 \mathrm{~km})$. The intrinsic frequency $(\hat{\omega})$ and period $(\hat{\tau})$ of the wave were approximately $0.01 \mathrm{~s}^{-1}$ and $10 \mathrm{~min}$ at the center of duct $(92 \mathrm{~km}$ ), and the average intrinsic frequency (or intrinsic period) in the evanescent regions below and above the duct was $0.0285 \mathrm{~s}^{-1}(\sim 3.8 \mathrm{~min})$.

The wind structure alone was able to support ducted smallscale wave propagation within a $\sim 10 \mathrm{~km}$ wide ducting region. Background winds Doppler-shift the intrinsic frequencies as they vary with height from maximum value to minimum value in the direction of wave propagation. The Doppler-shifted intrinsic frequency, $\left(\hat{\omega}=\omega-k u_{o}\right)$ was less than Brunt-Väisälä frequency, $N$ (or intrinsic period, $\hat{\tau}$ was greater than the Brunt-Väisälä period) in the vicinity of the maximum positive background wind at $92 \mathrm{~km}$ for the 5 July event (Chimonas and Hines, 1986).

Figure 2a also depicts the model horizontal wind $U_{o}(z)$, calculated from Eq. (5), using parameters based on wind observations, including amplitude of $\hat{U}=23 \mathrm{~m} / \mathrm{s}$ at reference height $z_{o}=92 \mathrm{~km}$, average vertical wavelength of $\Lambda_{z}=19 \mathrm{~km}$, and unperturbed mean background wind of $U_{b g}=-12 \mathrm{~m} / \mathrm{s}$. The analytical horizontal wind profile agrees well with the observed background wind profile at altitude of $80-100 \mathrm{~km}$, and is used in numerical model simulations presented in Sect. 4.3. As shown in Fig. $2 \mathrm{~b}, \mathrm{~m}^{2}$ using modeled horizontal wind is approximately consistent with the $m^{2}$ computed using observed background wind data, indicating positive peak of $m^{2}$ at altitude of $\sim 92 \mathrm{~km}$, and $\sim 10 \mathrm{~km}$ wide ducting region.

Figure 2c shows the time-altitude contour of background wind in the direction of wave propagation for the wave event recorded on the night of 5 July. Since observed phase speed of the wave was $37 \mathrm{~m} / \mathrm{s}$, background winds measuring 

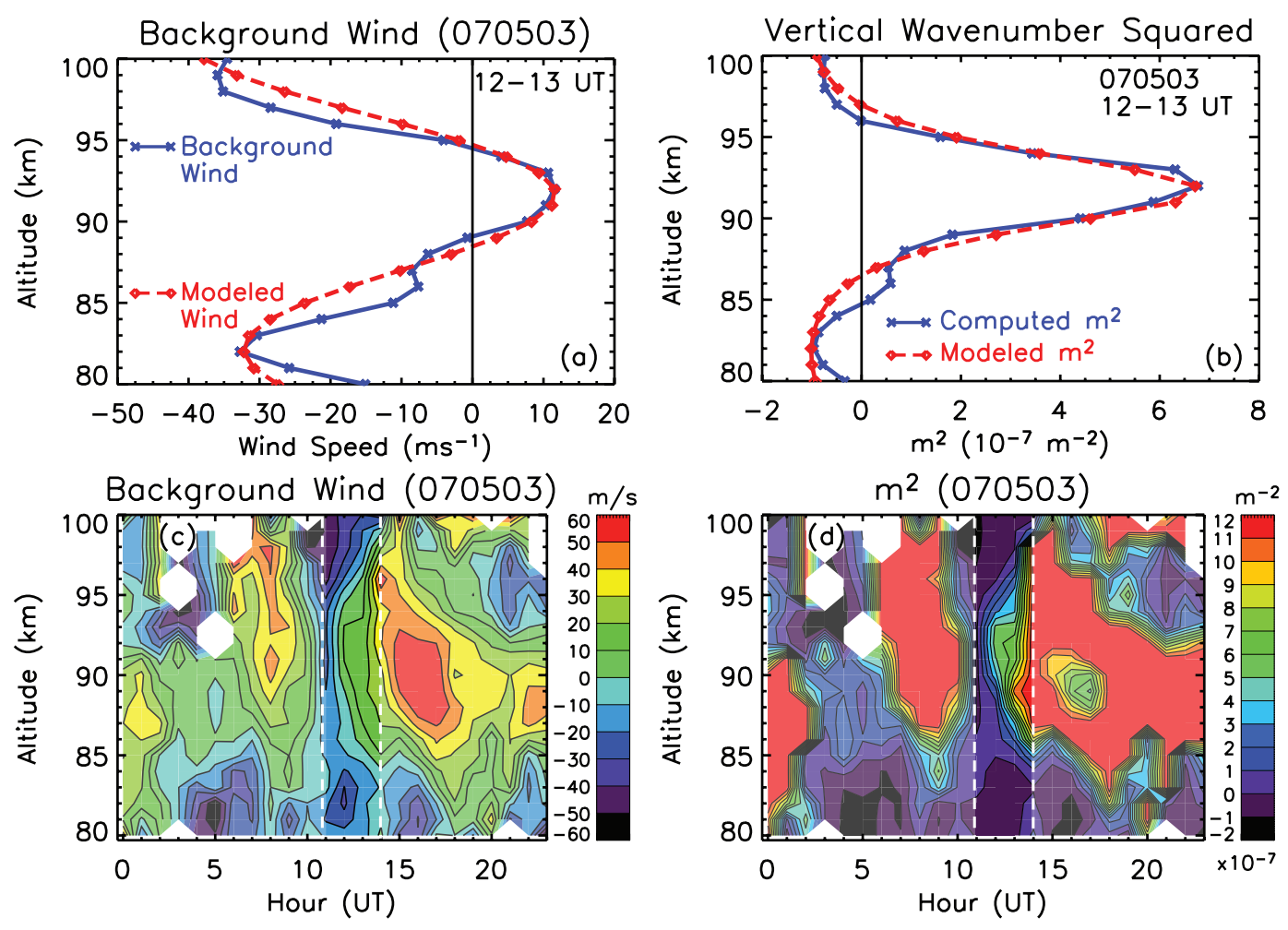

Fig. 2. Plots for 5 July 2003 ducted wave event depicting the vertical profiles of (a) measured (blue-solid) and modeled (red-dashed) background wind fields with respect to wave propagation, (b) the Taylor-Goldstein vertical wavenumber squared $\left(\mathrm{m}^{2}\right)$ computed for measured (blue-solid) and modeled (red-dashed) background wind fields. Contour plots depict (c) the measured background wind field over the course of the wave event (11:00-14:00 UT) and diurnal cycle, and (d) the calculated $m^{2}$ drived from background wind and wave parameters over the course of the wave event (11:00-14:00 UT) and diurnal cycle.

between $\sim 20 \mathrm{~m} / \mathrm{s}$ (positive) and $\sim 20 \mathrm{~m} / \mathrm{s}$ (negative) lead to a region of positive $m^{2}$ at the height range of $\sim 85-95 \mathrm{~km}$, while the negative background winds greater than $\sim 20 \mathrm{~m} / \mathrm{s}$ above $\sim 96 \mathrm{~km}$ and below $\sim 84 \mathrm{~km}$ lead to the regions of negative $m^{2}$ during the time of wave occurrence.

The structure of the background winds influence the nature of wave structure at the time of observation. At 12:00 UT, the positive (or negative) background winds less than $15 \mathrm{~m} / \mathrm{s}$ were able to make $m^{2}$ positive, providing a ducting region at $85-95 \mathrm{~km}$ altitude range, and significantly increasing negative background winds greater than $20 \mathrm{~m} / \mathrm{s}$ above and below this height range cause the region of negative $m^{2}$. Figure $2 \mathrm{~d}$ plots the time-height contour of $\mathrm{m}^{2}$ derived from TaylorGoldstein equation using hourly background wind in the direction of wave propagation. This shows that the propagation region $\left(m^{2}>0\right)$ of the wave in the duct was formed at the height range $\sim 85-95 \mathrm{~km}$ bounded by evanescent regions $\left(m^{2}<0\right)$ at the top and bottom sides of the duct during the time of wave occurrence. From 10:00 UT to 11:00 UT, a similar wave would have been nearly evanescent for a large altitude range. At 14:00 UT and later, the wave would be able to propagate over an expanding altitude range, and po- tentially subject to critical level dissipation as the wind approaches and eventually exceeds its horizontal phase velocity. Thus, the ducting region was significantly modulated in width, depth, and altitude over time as the wave was observed.

\subsection{November 2003: evanescent wave event}

Figure 1c and d shows small-scale wave structures imaged respectively in $\mathrm{OH}$ emission at 15:16 UT and the $\mathrm{O}_{2}$ emission at 15:19 UT on 30 November. This event extended over the entire field of view as coherent waves in both $\mathrm{OH}$ and $\mathrm{O}_{2}$ emissions, progressing southwest at $\sim 250^{\circ} \pm 4^{\circ}$, as measured clockwise from north. The arrow indicates the direction of the wave propagation. The horizontal wave parameters were derived from several successive images, with average horizontal wave wavelength, phase speed and observed period determined to be $\sim 17 \pm 1 \mathrm{~km}, \sim 25 \pm 3 \mathrm{~m} / \mathrm{s}$ and $\sim 11 \pm 1 \mathrm{~min}$, respectively. The wave event duration was $\sim 140$ min observed from 13:20 to 15:40 UT in $\mathrm{OH}$ emission and from 13:23 to $15: 43$ UT in $\mathrm{O}_{2}$ emission.

Figure $3 \mathrm{a}$ plots vertical profile of the background wind $\left(u_{o}\right)$ along the observed direction of horizontal motion of the 

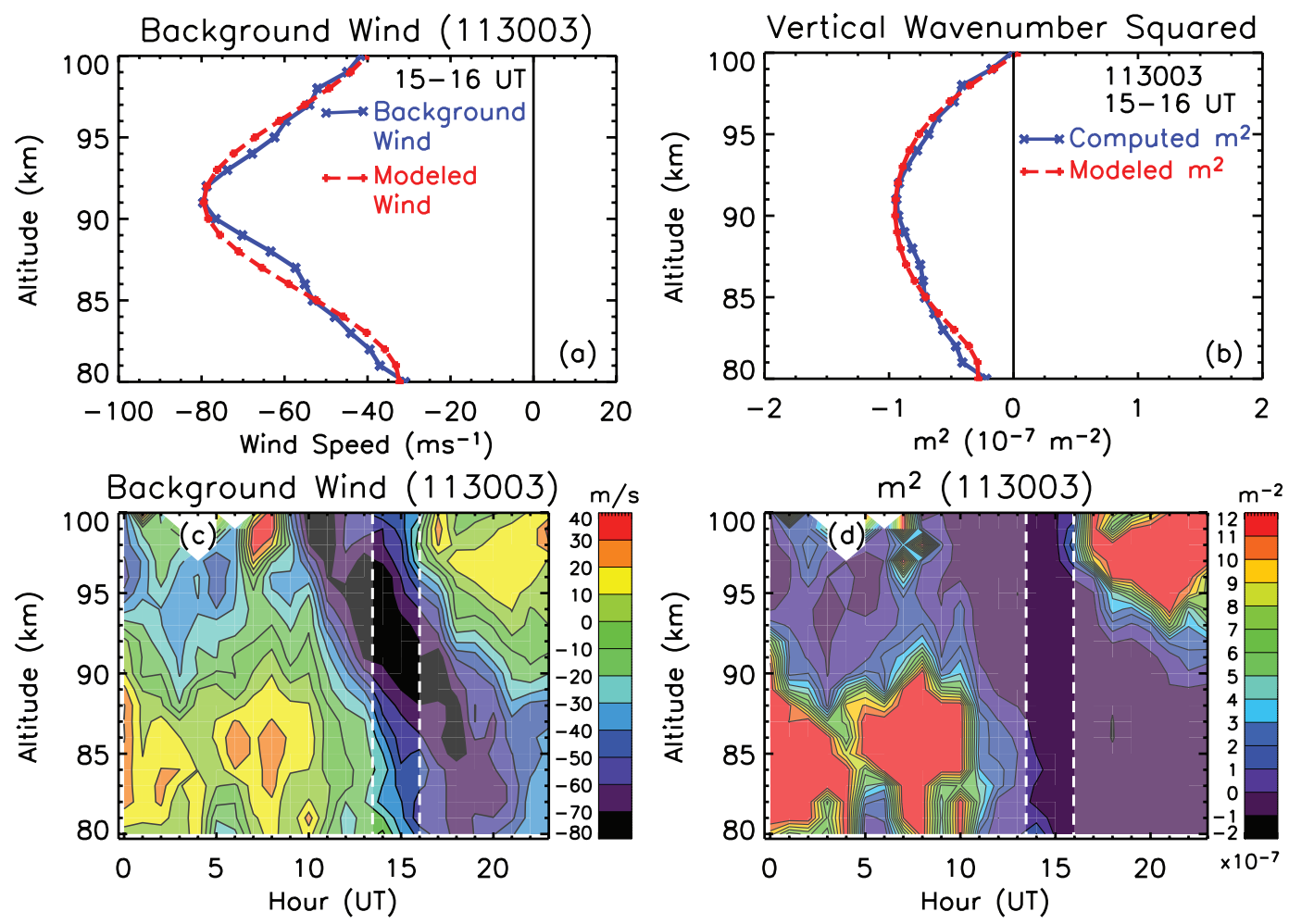

Fig. 3. Plots for 30 November 2003 evanescent wave event depicting the vertical profiles of (a) the measured (blue-solid) and modeled (reddashed) background wind fields with respect to wave propagation, (b) the Taylor-Goldstein vertical wavenumber squared $\left(\mathrm{m}^{2}\right)$ computed for measured (blue-solid) and modeled (red-dashed) background wind fields. Contour plots depict (c) the measured background wind field over the course of the wave event (13:00-16:00 UT) and diurnal cycle, and (d) the calculated $m^{2}$ drived from background wind and wave parameters over the course of the wave event (13:00-16:00 UT) and diurnal cycle.

wave at the time of 15:00-16:00 UT. This profile shows the strong negative background winds, clearly directed opposite to the wave motion over the altitude range of $80-100 \mathrm{~km}$. The maximum of the projected background wind in the opposite direction of wave motion was $\sim 80 \mathrm{~m} / \mathrm{s}$ at $91 \mathrm{~km}$ height. The magnitude of background wind gradually decreased below and above this peak height. For this analysis, we have recorded the measurement uncertainty as the standard deviation of the mean to be $\sim 4$ and $\sim 5 \mathrm{~m} / \mathrm{s}$ for zonal and meridional winds over $80-100 \mathrm{~km}$. Likewise, the calculated uncertainty for background wind as the standard deviation of the mean over height range of $80-100 \mathrm{~km}$ was $\sim 3 \mathrm{~m} / \mathrm{s}$.

As described above, we calculated local vertical wavenumber squared $\left(\mathrm{m}^{2}\right)$ from Eq. (2) using measured values of background wind $\left(u_{o}\right)$ and observed horizontal wavenumber $\left(k=2 \pi / \lambda_{x}\right)$ with a scale height $(H=6 \mathrm{~km})$ and $N^{2}$ obtained from MSISE-90 atmospheric model temperature profile (Hedin, 1991) as shown in Fig. 4b. Again, to confirm that the MSISE-90 data is approximately valid for these observations, the average Brunt-Väisälä frequency was derived from MTM temperature data. The $\mathrm{OH}$ and $\mathrm{O}_{2}$ temperatures were found to be $208 \mathrm{~K}$ and $213 \mathrm{~K}$, respectively, leading to an average $N^{2}$ of $0.000466 \mathrm{~s}^{-2}$, consistent with the MSIS model data. The small temperature gradient again suggests that significant inversion layers were not present in the airglow region during the time of the event.

Figure $3 \mathrm{~b}$ shows computed $\mathrm{m}^{2}$ for this event, revealing strong evanescence $\left(m^{2}<0\right)$ over the $80-100 \mathrm{~km}$ range encompassing the $\mathrm{OH}$ and $\mathrm{O}_{2}$ emission layer peaks with minimum $\mathrm{m}^{2}$ of $\sim-0.9 \times 10^{-7} \mathrm{~m}^{-2}$ at $91 \mathrm{~km}$ altitude. This was due to the large negative background winds encountered by the wave of small phase speed $\sim 25 \mathrm{~m} / \mathrm{s}$ throughout the range of the wind field. The greater increase in the magnitude of $\left(c-u_{o}\right)^{2}$ due to large negative background winds contributes to the negative $m^{2}$ in this region. The maximum value of intrinsic phase speed $\left(c-u_{o}\right)$ of $\sim 105 \mathrm{~m} / \mathrm{s}$ of the wave suggests a minimum intrinsic period of $\hat{\tau}=2.7 \mathrm{~min}$ at $91 \mathrm{~km}$, and the average period $(\hat{\tau})$ over the $80-100 \mathrm{~km}$ height range was $3.6 \mathrm{~min}$. The intrinsic phase speeds $\left(c-u_{o}\right)$ gradually decrease below and above the peak height with slower negative background wind flow, but remain large enough for $m^{2}$ to be negative over a large region, suggesting the wave was likely evanescent in nature from $80-100 \mathrm{~km}$. This indicates higher intrinsic frequency (and lower intrinsic period) than 
the Brunt-Väisälä frequency (and Brunt-Väisälä period) of the evanescent wave. Therefore, in order for the wave to have been propagating, rather than evanescent, at this altitude, the Brunt-Väisälä period would need to be $<2.7 \mathrm{~min}$ over a range of several kilometers, which is highly unlikely given the measured height-averaged MTM temperatures and estimated $N^{2}$ of $0.000466 \mathrm{~s}^{-2}$, suggesting a Brunt-Väisälä period of $4.85 \mathrm{~min}$.

Figure $3 \mathrm{a}$ also depicts the model horizontal wind $U_{o}(z)$ as calculated from Eq. (5). The parameters used for the modeled wind profile include amplitude of $\hat{U}=-22 \mathrm{~m} / \mathrm{s}$ at reference height $z_{o}=91 \mathrm{~km}$, average vertical wavelength $\Lambda_{z}=22 \mathrm{~km}$ and unperturbed mean background wind of $U_{b g}=-57 \mathrm{~m} / \mathrm{s}$. The modeled horizontal wind profile agrees well with the observed background wind profile over the range of $80-100 \mathrm{~km}$. This modeled horizontal wind was then inserted in Eq. (2) to derive the vertical wavenumber squared $\left(\mathrm{m}^{2}\right)$. As shown in Fig. 3b, the profile of negative values of the modeled $m^{2}$ agree well with the negative value of computed $m^{2}$, leading to the strong evanescence.

Figure $3 \mathrm{c}$ shows time-altitude contour plot of the background wind in the direction of wave propagation as derived from the zonal and meridional wind components for 30 November event. The strong background wind opposite to the direction of wave motion was progressed down from $100 \mathrm{~km}$ to $80 \mathrm{~km}$ at $\sim 09: 00-23: 00$ UT time. Because of the average observed phase speed $(25 \mathrm{~m} / \mathrm{s})$ of the wave, the average negative background wind of $57 \mathrm{~m} / \mathrm{s}$ measured between 13:00 and 16:00 UT leads to the region of negative $m^{2}$ where the wave was occurred. At 15:00 UT, the negative background wind of $\sim 80 \mathrm{~m} / \mathrm{s}$ was measured at $91 \mathrm{~km}$ and then negative background wind magnitudes decreased from this peak height to $\sim 31 \mathrm{~m} / \mathrm{s}$ at $80 \mathrm{~km}$ and $\sim 42 \mathrm{~m} / \mathrm{s}$ at $100 \mathrm{~km}$.

Figure $3 \mathrm{~d}$ plots the time-height contour of $m^{2}$ derived from Taylor-Goldstein equation using hourly background wind in the direction of wave propagation. Because of strong negative background the plot shows the evanescent region $\left(m^{2}<0\right)$ progressing down from $\sim 09: 00 \mathrm{UT}$ at $100 \mathrm{~km}$ to 23:00 UT at $80 \mathrm{~km}$. The derived negative values of $\mathrm{m}^{2}$ indicated that the evanescent region was occurred at the altitude range of $88-100 \mathrm{~km}$ at $13: 00$ UT and of $80-98 \mathrm{~km}$ at 14:00 UT, with variation of background winds. At 15:00 UT, evanescent region extended throughout the range of 80 $100 \mathrm{~km}$. The region of negative $\mathrm{m}^{2}$ occurred due to the presence of large background wind speed in the opposite direction of the wave motion, causing the wave of observed speed $25 \mathrm{~m} / \mathrm{s}$ to be purely evanescent in this region. However, the wave was likely able to propagate above the region of evanescence, especially at later times after 15:00-16:00 UT.

\subsection{Numerical model simulation}

Numerical simulation results are obtained with the model of Snively and Pasko (2008), using the CLAWPACK software package (http://www.amath.washington.edu/ claw). Back-
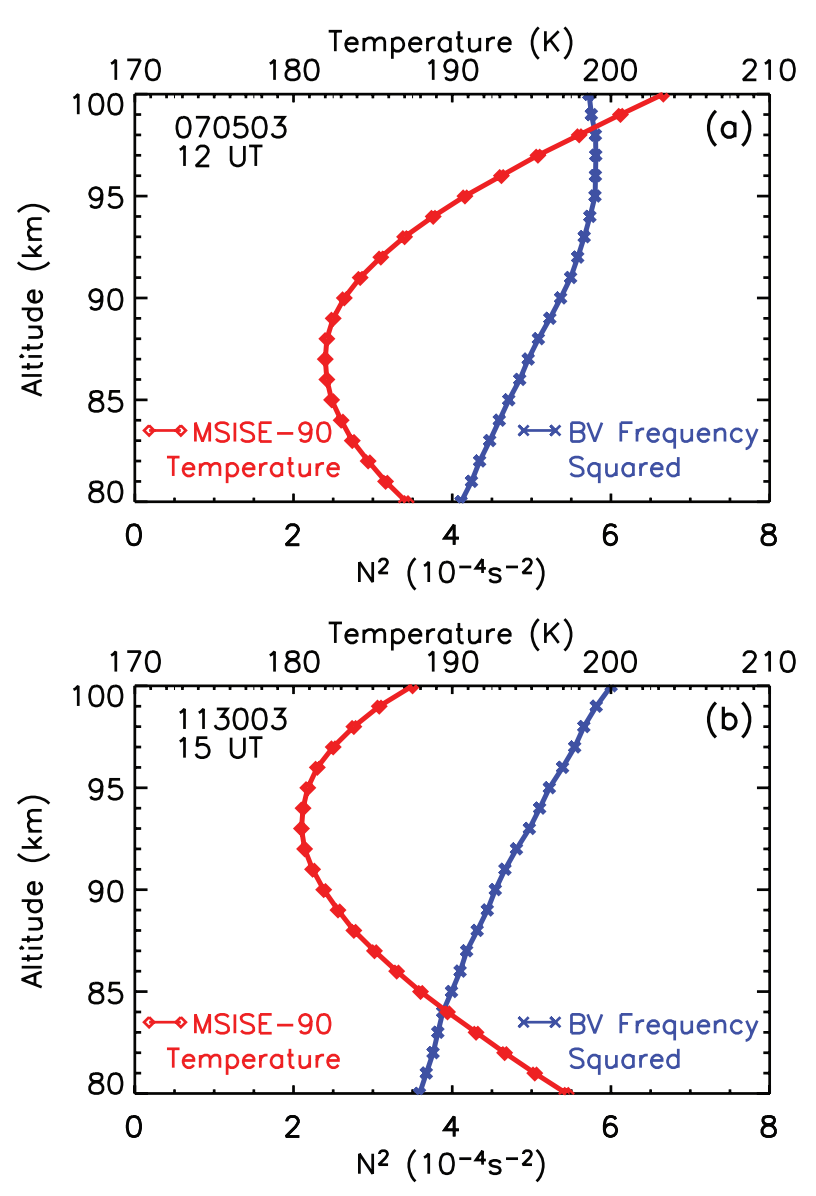

Fig. 4. The plots depict the MSISE-90 model temperature (red) and Brunt-Väisälä frequency squared (blue) profiles for (a) 5 July 2003 ducted wave event at 12:00 UT, and (b) 30 November 2003 evanescent event at 15:00 UT.

ground atmospheric conditions use the analytic model wind profiles depicted in Figs. 2a and 3a, along with MSISE-90 temperature and neutral density fields obtained for the times and locations of the events (Hedin, 1991). Increasing molecular kinematic viscosity and thermal conduction naturally damps waves that propagate vertically towards the upper boundary, with no auxiliary sponge layer (Snively and Pasko, 2008, and references cited therein). The domain boundaries extend from -500 to $+500 \mathrm{~km}$ in the horizontal direction $(1000 \mathrm{~km}$ total), and 0 to $220 \mathrm{~km}$ in the vertical direction, with $0.5 \mathrm{~km}$ uniform grid spacing.

Waves are generated using a vertical force applied by an idealized momentum source located near tropopause. The source is a traveling wave oscillator with Gaussian form that excites waves principally in the "rightward" horizontal direction. The source of the gravity waves is positioned at $x_{o}=0 \mathrm{~km}$ and $z_{o}=12 \mathrm{~km}$ (i.e., $500 \mathrm{~km}$ from the left boundary of the simulation domain and

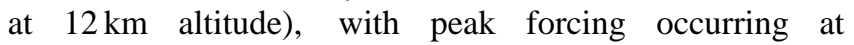




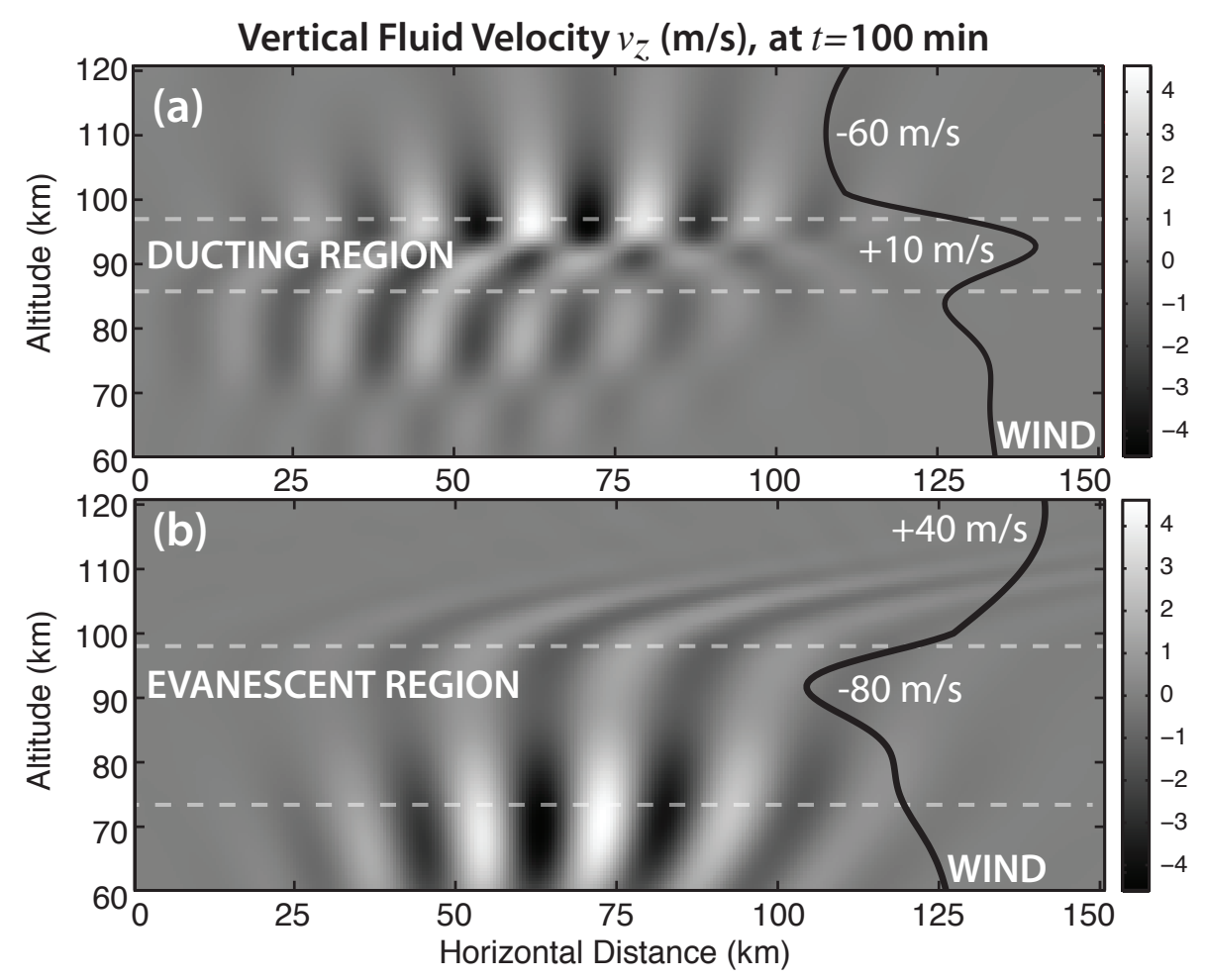

Fig. 5. Model simulation results depicting upward wave propagation through the mesopause region, for (a) wind profile consistent with nonideal Doppler ducting from $87-97 \mathrm{~km}$, based on the wave event of 5 July 2003, and (b) wind profile consistent with evanescent propagation from $75-100 \mathrm{~km}$, based on the wave event of 30 November 2003. In both (a) and (b), data is plotted at a time 100 min after start of the model simulation. The waves are seen refracted by the ambient wind field, leading to regions of propagation and evanescence, and thus weak trapping.

$t_{o}=1500 \mathrm{~s}$. It provides a vertical force at a chosen frequency $(\omega)$ and horizontal wavenumber $\left(k_{x}\right)$ of the form $\sim \exp \left[-\left(x-x_{o}\right)^{2} / 2 \sigma_{x}^{2}-\left(z-z_{o}\right)^{2} / 2 \sigma_{z}^{2}-\left(t-t_{o}\right)^{2} / 2 \sigma_{t}^{2}\right] \cos [\omega t$ $\left.-k_{x}\left(x-x_{o}\right)-k_{z}\left(z-z_{o}\right)\right]$, where $\sigma_{x}$ and $\sigma_{z}$ are the Gaussian envelope's horizontal and vertical half-widths, respectively, and $\sigma_{t}$ is the temporal Gaussian half-width; the position given by $x_{o}, z_{o}$, and $t_{o}$ corresponds to the source maximum in space and time. The source characteristics are consistent with observed ground-relative wave parameters. For the ducted wave case study, parameters are defined: $\omega=0.0155 \mathrm{rad} / \mathrm{s} \quad(T=6.75 \mathrm{~min}), \quad k_{x}=4.18 \times 10^{-4} \mathrm{rad} / \mathrm{m}$ $\left(\lambda_{x}=15 \mathrm{~km}\right), k_{z}=0, \sigma_{x}=15 \mathrm{~km}, \sigma_{z}=3 \mathrm{~km}$, and $\sigma_{t}=25 \mathrm{~min}$. For the evanescent wave case study, parameters are defined: $\omega=0.0092 \mathrm{rad} / \mathrm{s}(T=11.38 \mathrm{~min}), k_{x}=3.7 \times 10^{-4} \mathrm{rad} / \mathrm{m}$ $\left(\lambda_{x}=17 \mathrm{~km}\right), k_{z}=0, \sigma_{x}=15 \mathrm{~km}, \sigma_{z}=3 \mathrm{~km}$, and $\sigma_{t}=25 \mathrm{~min}$.

Figure 5a depicts the numerical model results for the Doppler-ducted wave simulation (5 July Case Study), at a time $100 \mathrm{~min}$ after the initial turn-on of the source. The wave propagates within the analytical wind profile shown in Fig. 2a. It has been assumed that the wave is forced from below by a tropospheric source, and becomes trapped via linear tunneling into the duct through the evanescent boundary near $80-85 \mathrm{~km}$ altitude. This simple case of ducted wave excita- tion is consistent with the process described by Walterscheid et al. (2001). This forms a robust mechanism for wave excitation at mesopause altitudes, particularly for waves of 6$8 \mathrm{~min}$ ground-relative periods. The wind graphic overlaying the numerical results illustrates the approximate local wind profile. It is clear that the propagation region of the ducted wave is concentrated near the wind peak region occurring at $\sim 90 \mathrm{~km}$, with evanescent standing wave structure above and below. Ducted propagation also occurs below $\sim 75 \mathrm{~km}$, as the wave is able to propagate at lower altitudes in the mesosphere. It is important to note that this wave is a non-ideally ducted packet, and it will exhibit propagation loss and periodic upward and downward momentum flux as it propagates (e.g., Yu and Hickey, 2007). Local wave-induced vertical wind velocities are on the order of a few $\mathrm{m} / \mathrm{s}$ at $\sim 90 \mathrm{~km}$, with peak velocities near $\sim 10 \mathrm{~m} / \mathrm{s}$, and may be expected to lead to strong perturbations of the airglow layers (Hickey, 2001; Snively et al., 2007). At larger magnitude, breaking of the wave within or above the duct may occur.

Figure $5 \mathrm{~b}$ depicts the numerical model results for the evanescent wave simulation (30 November Case Study), excited within the analytically specified wind field depicted in Fig. 3a. Again, the wave is forced from below by a 
tropospheric source, and reaches evanescence at $\sim 75 \mathrm{~km}$ altitude. The gradual shift to near-infinite vertical wavelength leads to strong standing wave structure below the evanescent layer, where the wave experiences gradual downward reflection. Simultaneously, a portion of wave energy tunnels through this layer of evanescence, to emerge above at $\sim 100 \mathrm{~km}$ altitude. The positive wind flow leads to relatively small vertical wavelengths, and thus enhanced dissipation by viscosity. The wave-induced vertical winds are again on the order of a few $\mathrm{m} / \mathrm{s}$ within the $\mathrm{OH}$ and $\mathrm{O}_{2}$ airglow layers, and quite sufficient for measurable perturbations of airglow emissions intensity to arise. Given the relatively strong gravity wave activity present in the model throughout mesopause, despite evanescence, it appears quite reasonable that waves propagating upward from below could explain the observed signatures. Actual wave magnitude, and airglow intensity variations, would thus be determined by original source intensity.

Model results suggest that, in both cases, the dominant airglow signatures may have arisen from the evanescent standing wave structure, which is present throughout the airglow region (note wave structures at $95-100 \mathrm{~km}$ and $80-85 \mathrm{~km}$ in Fig. 5a, and 75-95 km in Fig. 5b). Such waves are quite effective at perturbing the airglow layers (e.g., Hines and Tarasick, 1994; Snively et al., 2007), as a result of the long vertical wavelengths, and nearly vertical polarization, which enhance density perturbations to layered minor species. Detailed modeling of ducted and evanescent wave perturbations to airglow layers will be explored in a separate paper by Snively et al.

\section{Conclusions}

Simultaneous airglow image measurements in the $\mathrm{OH}$ and $\mathrm{O}_{2}$ emissions from a mesosphere temperature mapper (MTM) have been used to investigate the horizontal parameters of small-scale ducted and evanescent gravity waves, and their propagation characteristics. Average observed wave parameters of 15 events include horizontal wavelengths of $\sim 18 \mathrm{~km}$, phase speeds of $\sim 37 \mathrm{~m} / \mathrm{s}$, and observed periods of $\sim 8 \mathrm{~min}$. Coincident meteor radar wind data have been used to investigate the intrinsic properties of these waves. This analysis reveals that 9 of the total wave events were Doppler ducted and 6 of them were evanescent in the mesopause airglow region. All exhibit relatively similar airglow signatures.

Two wave events were selected for numerical case studies. The first of the two wave events studied was clearly ducted in the airglow region. Observations strongly indicate that the wave event was trapped non-ideally in a welldefined $\sim 10 \mathrm{~km}$ wide Doppler duct that persisted for $\sim 3 \mathrm{~h}$, coinciding with the approximate duration of observation. The second wave event exhibited similar wave characteristics (wavelength, and observed phase velocity and period), but was purely evanescent throughout the $80-100 \mathrm{~km}$ region, as a consequence of strong opposing background winds. $\mathrm{Nu}-$ merical model simulations indicate that the measured ducted and evanescent wave events are consistent with theoretical Doppler-ducted and evanescent wave characteristics. In both cases the background winds strongly influenced the observability of the waves and the local wave vertical structure. Despite the obstacle of evanescence, model results indicate that it is quite reasonable for the observed waves to have been generated by tropospheric convective sources (e.g., Alexander, 1996), and to be of sufficient intensity to be detectable in airglow data.

Acknowledgements. We gratefully acknowledge the use of the US Air Force AMOS facility and staff and for their considerable help with our long-term Maui-MALT measurements. This research was supported under NSF grant ATM-0455259 to Utah State University. Work by J. B. Snively was supported under NSF CEDAR post-doctoral grant ATM-0725317 to Utah State University. Meteor radar data were obtained under NSF grant ATM-0003182 to University of Illinois at Urbana-Champaign.

Topical Editor K. Kauristie thanks two anonymous referees for their help in evaluating this paper.

\section{References}

Alexander, M. J.: A Simulated Spectrum of Convectively Generated Gravity Waves: Propagation From the Troposphere to the Mesosphere and Effects on the Middle Atmosphere, J. Geophys. Res., 101, 1571-1588, 1996.

Chimonas, G. H. and Hines, C. O.: Doppler ducting of atmospheric gravity waves, J. Geophys. Res., 91, 1219-1230, 1986.

Chu, X., Gardner, C. S., and Franke, S. J.: Nocturnal thermal structure of the mesosphere and lower thermosphere region at Maui, Hawaii $\left(20.7^{\circ} \mathrm{N}\right)$ and Starfire Optical Range, New Mexico (35 $)$, J. Geophys. Res., 110, D09S03, doi:10.1029/2004JD004891, 2005.

Coble, M., Papen, G. C., and Gardner, C. S.: Computing twodimensional unambiguous horizontal wavenumber spectrafrom $\mathrm{OH}$ airglow images, Geoscience and Remote Sensing, IEEE Transactions, 41, 146-152, doi:10.1109/36.662723, 2003.

Dewan, E. M. and Picard, R. H.: Mesospheric Bores, J. Geophys. Res., 103, 6295-6305, 1998.

Franke, S. J., Chu, X., Liu, A. Z., and Hocking, W. K.: Comparison of meteor radar and $\mathrm{Na}$ Doppler lidar measurements of winds in the mesopause region above Maui, Hawaii, J. Geophys. Res., 110, D09S02, doi:10.1029/2003JD004486, 2005.

Fritts, D. C. and Alexander, M. J.: Gravity wave dynamics and effects in the middle atmosphere, Rev. Geophys., 41, 1003, doi: 10.1029/2001RG000106, 2003.

Fritts, D. C. and Yuan, L.: An Analysis of Gravity Wave Ducting in the Atmosphere: Eckart's Resonances in Thermal and Doppler Ducts, J. Geophys. Res., 94, 18455-18466, 1989.

Garcia, F. J., Taylor, M. J., and Kelley, M. C.: Two-dimensional spectral analysis of mesospheric airglow image data, Appl. Optics, 36, 7374-7385, 1997.

Gossard, E. E. and Hooke, W. H.: Waves in the Atmosphere, Elsevier Scientific, 1975. 
Hecht, J. H.: Instability layers and airglow imaging, Rev. Geophys., 42, RG1001, doi:10.1029/2003RG000131, 2004.

Hecht, J. H., Walterscheid, R. L., Hickey, M. P., and Franke, S. J.: Climatology and Modeliing of Quasi-Monochromatic Atmospheric Gravity Waves Observed Over Urbana, Illinois, J. Geophys. Res., 106, 5181-5195, 2001.

Hedin, A. E.: Extension of the MSIS thermospheric model into the middle and lower atmosphere, J. Geophys. Res., 96, 1159-1172, 1991.

Hickey, M. P.: Airglow Variations Associated With Nonideal Ducting of Gravity Waves in the Lower Thermosphere Region, J. Geophys. Res., 106, 17907-17917, 2001.

Hines, C. O. and Tarasick, D. W.: Airglow response to vertically standing gravity waves, Geophys. Res. Lett., 21, 2729-2732, 1994.

Hocking, W. K. and Thayaparan, T.: Simultaneous and colocated observations of winds and tides by $\mathrm{MF}$ and meteor radars over London, Canada ( $43^{\circ} \mathrm{N}, 81^{\circ} \mathrm{W}$ ), during 1994-1996, Radio Sci., 32, 833-865, 1997.

Hocking, W. K., Fuller, B., and Vandepeer, B.: Real-time determination of meteor-related parameters utilizing modern digital technology, J. Atmos. Solar-Terr. Phys., 63, 155-169, 2001.

Isler, J. R., Taylor, M. J., and Fritts, D. C.: Observational Evidence of Wave Ducting and Evanescence in the Mesosphere, J. Geophys. Res., 102, 26301-26313, 1997.

Meriwether, J. W.: Ground based measurements of mesospheric temperatures by optical means, MAP Handb., 13, 1-18, 1984.

Nappo, C. J.: An introduction to atmospheric gravity waves, Amsterdam: Academic Press, 2002 International geophysics series, vol. 85, ISBN 0125140827., 2002.

Pautet, D. and Moreels, G.: Ground-based satellite-type images of the upper-atmosphere emissive layer, Appl. Optics, 41, 823-831, 2002.

Pendleton, W. R., J., Taylor, M. J., and Gardner, L. C.: Terdiurnal oscillations in $\mathrm{OH}$ Meinel rotational temperatures for fall conditions at northern mid-latitude sites, Geophys. Res. Lett., 27, 1799-1802, 2000.

Snively, J. B. and Pasko, V. P.: Breaking of thundestorm-generated gravity waves as a source of short-period ducted waves at mesopause altitudes, Geophys. Res. Lett., 30, 2254, doi:10.1029/ 2003GL018436, 2003.

Snively, J. B. and Pasko, V. P.: Excitation of ducted gravity waves in the lower thermosphere by tropospheric sources, J. Geophys. Res., 113, A06303, doi:10.1029/2007JA012693, 2008.
Snively, J. B., Pasko, V. P., Taylor, M. J., and Hocking, W. K.: Doppler ducting of short-period gravity waves by midlatitude tidal wind structure, J. Geophys. Res., 112, A03304, doi:10. 1029/2006JA011895, 2007.

Sutherland, B. R. and Yewchuk, K.: Internal wave tunnelling, J. Fluid Mech., 511, 125-134, 2004.

Taylor, M. J. and Edwards, R.: Observations of Short Period Mesospheric Wave Patterns: In situ or Tropospheric Wave Generation?, Geophys. Res. Lett., 28, 1337-1340, 1991.

Taylor, M. J., Turnbull, D. N., and Lowe, R. P.: Spectrometric and Imaging Measurements of a Spectacular Gravity Wave Event Observed During the ALOHA-93 Campaign, Geophys. Res. Lett., 22, 2849-2852, 1995.

Taylor, M. J., Pendleton, W. R., J., Clark, S., Takahashi, H., Gobbi, D., and Goldberg, R. A.: Image measurements of short-period gravity waves at equatorial latitudes, J. Geophys. Res., 102, 26283-26299, 1997.

Taylor, M. J., Pendleton, W. R., Gardner, C. S., and States, R. J.: Comparison of terdiurnal tidal oscillations in mesospheric $\mathrm{OH}$ rotational temperature and $\mathrm{Na}$ lidar temperature measurements at mid-latitudes for fall/spring conditions, Earth, Planets, Space, 51, 877-885, 1999.

Taylor, M. J., Gardner, L. C., and Pendleton, W. R.: Long-period wave signatures in mesospheric $\mathrm{OH}$ Meinel $(6,2)$ band intensity and rotational temperature at mid-latitudes, Adv. Space Res., 27, 1171-1179, 2001.

Walterscheid, R. L., Hecht, J. H., Vincent, R. A., Reid, I. M., Woithe, J., and Hickey, M. P.: Analysis and Interpretation of Airglow and Radar Observations of Quasi-Monochromatic Gravity Waves in the Upper Mesosphere and Lower Thermosphere over Adelaide, Australia, J. Atmos. Solar-Terr. Phys., 61, 461-478, 1999.

Walterscheid, R. L., Hecht, J. H., Djuth, F. T., and Tepley, C. A.: Evidence of Reflection of a Long-Period Gravity Wave in Observations of the Nightglow Over Arecibo on May 8-9, 1989, J. Geophys. Res., 105, 6927-6934, 2000.

Walterscheid, R. L., Schubert, G., and Brinkman, D. G.: SmallScale Gravity Waves in the Upper Mesosphere and Lower Thermosphere Generated by Deep Tropical Convection, J. Geophys. Res., 106, 31825-31832, 2001.

Yu, Y. and Hickey, M. P.: Time-resolved ducting of atmospheric acoustic-gravity waves by analysis of the vertical energy flux, Geophys. Res. Lett., 34, L02821, doi:10.1029/2006GL028299, 2007. 